be doubled to bring the intracellular magnesium concentration down to the patient's figure (a little less than half the normal). The reason for the loss of the ability to maintain the normal concentration gradient across the cell wall is far from clear at the moment.

The rapid response of the mental changes to calcium is worth noting. Magnesium has a depressant action on the central and peripheral nervous system (Engbaek, 1952) and diminishes the amount of acetylcholine liberated at the neuromuscular junction (del Castillo and Engbaek, 1954). Calcium is known to antagonize these actions (Hutter and Kostial, 1954; Jenkinson, 1957). The response to calcium in the face of maintained hypermagnesaemia is in keeping with this antagonistic action of calcium. It is interesting, however, to note that the tendon reflexes were not restored with calcium therapy.

Although this patient was quite severely depleted of magnesium, probably for a considerable duration, he showed none of the outstanding clinical features of such depletion. In this particular situation it would appear that it was hypermagnesaemia and not the concomitant magnesium depletion which dominated the clinical picture.
We thank Dr. E. Jacob and the staff of the biochemistry department, Outram Road General Hospital, Singapore, for the biochemical estimations,

\section{REFERENCES}

del Castillo, J., and Engbaek, L. (1954). 7. Physiol. (Lond.), 124, 370. Engbaek, L. (1952). Pharmacol. Rev., 4, 396.

Hamburger, J. (1957). Clin. Chem., 3, 332

Hutter, O. F., and Kostial, K. (1954). F. Physiol. (Lond.), 124, 234

Jenkinson, D. H. (1957). F. Physiol. (Lond.), 138, 434.

MacIntyre, I. (1963). Sci. Basis Med., p. 218

Macintyre, 1. (1963). Sci. Basis Med., p. Riochem. 7., 70, 456.

MacIntyre, I. Hanna, S, Booth, C. C., and Read, A. E. (1961). Clin. Sci. 20, 297

Martin, H. E., and Jones, R. (1961). Amer. Heart f., 62, 206.

Nabarro, J. D. N., Spencer, A. G., and Stowers, J. M. (1952). Quart. 7. Med., 21, 225 .

Randall, R. E., jun., Cohen, M. D., Spray, C. C., jun., and Rossmeisl, E. C. (1964). Ann. intern. Med., 61, 73.

Robinson, R. R., Murdaugh, H. V., jun., and Peschel, E. (1959). F. Lab. clin. Med., 53, 572.

Seelig, M. S. (1964). Amer. f. clin. Nutr., 14, 342.

Shaw, A. B., Bazzard, F. J., Booth, E. M., Nilwarangkur, S., and Berlyne G. M (1965), Quart. 7. Med, 34, 237.

Smith, W. O., and Hammarsten, J. F. (1958). Arch. intern. Med., 102, 5 .

Takayasu, H., Sato, S., Yanadori, H., and Hirata, T. (1962). Acta med. biol. (Niigata), 10, 117.

\title{
Cutaneous Anthrax-the Non-industrial Hazard
}

\author{
A. H. KNIGHT,* M.B., B.S., M.R.C.P. ; C. J. E. WYNNE-WILLIAMS, † M.B., D.C.H., D.oBST.R.C.O.G.
}

A. T. WILLIS, $\ddagger$ M.D., PH.D., M.R.A.C.P.

Brit. med. F., 1969, 1, 416-418

Summary: Two patients contracted cutaneous anthrax $\checkmark$ after contact with infected bone meal. Awareness of the risk of infection from this source may help in achieving early clinical diagnosis and a low fatality rate following effective antibiotic therapy.

\section{Introduction}

Anthrax is an uncommon disease in the United Kingdom, yet bone-meal is widely used as a horticulture fertilizer. Two cases are presented, apparently not connected in any way, but occurring within 16 miles $(25 \mathrm{~km}$.) and nine days of each other. As neither patient works in an occupation known to carry an anthrax hazard, they show the possibility of infection in the general population.

\section{Case 1}

A 55-year-old builder was admitted to the isolation ward at Stoke Mandeville Hospital on 15 February 1968 with a swollen right elbow. Four days previously, while at work, he vaguely remembered being pricked through his jacket, and a swelling had developed at the site of the puncture. It had progressed rapidly, and on the day of admission he was febrile (temperature $102.2^{\circ} \mathrm{F} . ; 39^{\circ} \mathrm{C}$.) and toxic, with brawny oedema of the entire upper limb and a "malignant pustule" on the lateral aspect of the elbow (Fig. 1), discharging a brownish exudate. There were tender, enlarged lymph nodes in the right axilla.

* Medical Registrar, Luton and Dunstable Hospital, Luton. Present address: Royal Free Hospital, North-west Branch, Lawn Road, London N.W.3.

+ Medical Registrar, Stoke Mandeville Hospital, Aylesbury.

¥ Director, Public Health Laboratory, Luton.
About six weeks before admission he had scattered $2 \mathrm{lb} .(0.9 \mathrm{~kg}$.) of bone-meal on his chrysanthemum plot while he was wearing the same jacket. Knowing the risk to his health, he had in fact worn rubber gloves for handling the meal.

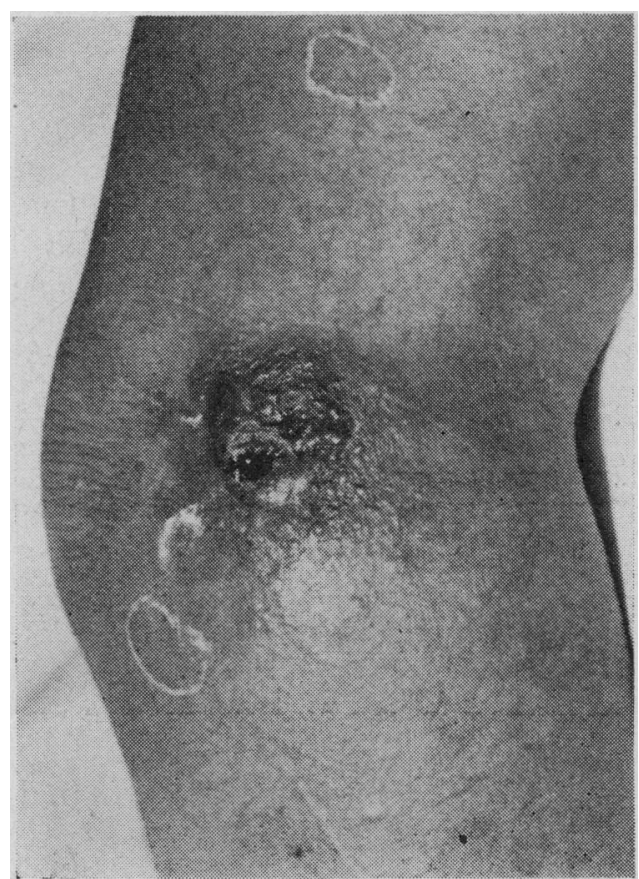

FIG. 1.-Case 1. Malignant pustule.

There was a purulent exudate from the pustule. Microscopical examination showed that it contained cellular debris and scanty but easily recognizable Gram-positive bacilli. Culture grew the typical 
Medusa-head colonies of Bacillus anthracis, and inoculated mice died spontaneously within 24 hours with the distinctive features of anthrax, including septicaemia and splenomegaly. B. anthracis was further identified by its biochemical and cultural reactions.

Treatment was started with penicillin (one mega unit four-hourly), but after 24 hours he was still toxic, and so parenteral streptomycin was added for five days. The fever subsided after 48 hours of this combined therapy. Seven days after admission he developed a sensitivity rash, presumably due to the penicillin, and the antibiotics were changed to oral tetracycline $(250 \mathrm{mg}$. six-hourly) for a further 10 days. The oedema subsided after a week's treatment but three months elapsed before the scab finally resolved. There was no residual disability.

\section{Case 2}

A 63-year-old groundsman was admitted to the isolation unit of the Luton and Dunstable Hospital on 24 February 1968 complaining of swelling of the face. Three days before admission considerable swelling of the left side of his face had developed over the course of 12 hours. The centre of the swelling had caused irritation, and after the application of local heat a clear discharge had resulted. The central zone subsequently became black. Ten days before the onset of symptoms he had spread $5 \mathrm{cwt} .(254 \mathrm{~kg}$.) of bone-meal fertilizer on to the ground, taking no special precautions during the procedure. $\mathrm{He}$ had no recollection of any cuts or abrasions to the face.

On admission his temperature was $101.4^{\circ} \mathrm{F} .\left(38.6^{\circ} \mathrm{C}.\right)$, but he did not complain of either pain or constitutional symptoms. There was extensive brawny oedema over the left mandible with a central black, scaly area 1 in. $(2.5 \mathrm{~cm}$.) in diameter, the edge of which was vesicular. A small satellite lesion was present below the main area. There was no lymphadenopathy. Cutaneous anthrax was diagnosed (Fig. 2).

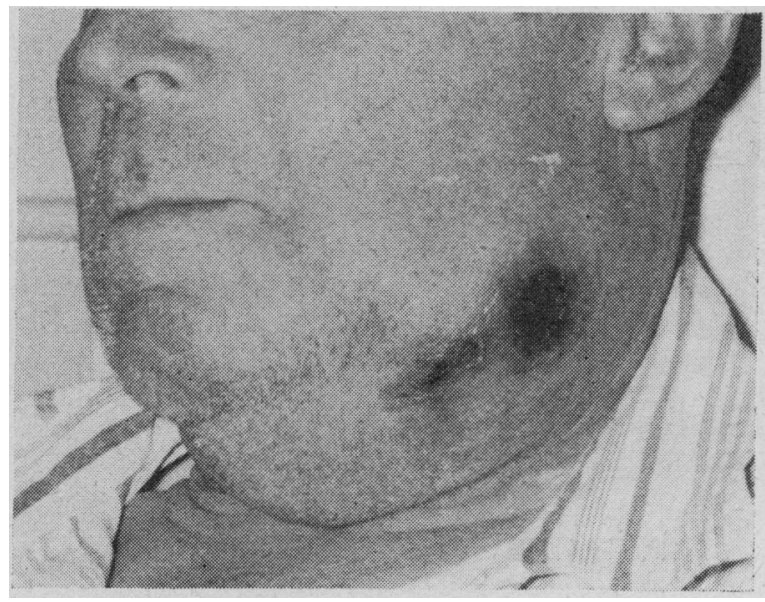

Fig. 2.-Case 2. Malignant pustule.

Films of the exudate from the "malignant pustule," stained by the methods of Gram and Leishman, showed an occasional polymorphonuclear leucocyte only; no organisms were seen. Direct plating of the exudate on to fresh horse-blood agar yielded a scanty growth of $B$. anthracis, together with colonies of Staphylococcus albus, after 24 hours' incubation. The anthrax bacillus was identified subsequently in pure culture and was kindly confirmed by Dr. Joan Davies at the Anthrax Reference Laboratory (Figs. 3 and 4).

The patient was treated with penicillin, one mega unit six-hourly for 12 days. He became aprexial after 48 hours, the oedema subsided after seven days, and the remaining eschar slowly separated over a further four weeks.

\section{Discussion}

Both these cases illustrate the clinical features of cutaneous anthrax, treated at an early stage with antibiotics, before the onset of severe constitutional symptoms indicative of septicaemia or meningitis. From the history in each case bone-meal appeared to be the most likely source of infection.
Detailed work and investigation by the public health authorities and H.M. Factory Inspectorate (Dr. D. G. Trott, H.M. Divisional Medical Inspector of Factories) followed, but it was not possible to demonstrate the infecting organism from clothing, residual samples of meal, or the retailer's premises.

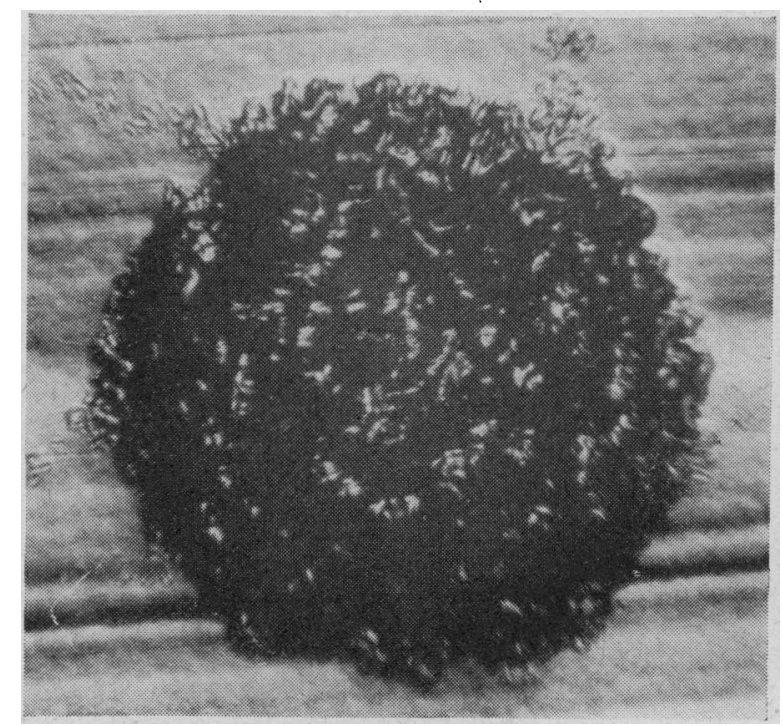

FIG. 3.-Medusa-head colony. $(\times 11$.

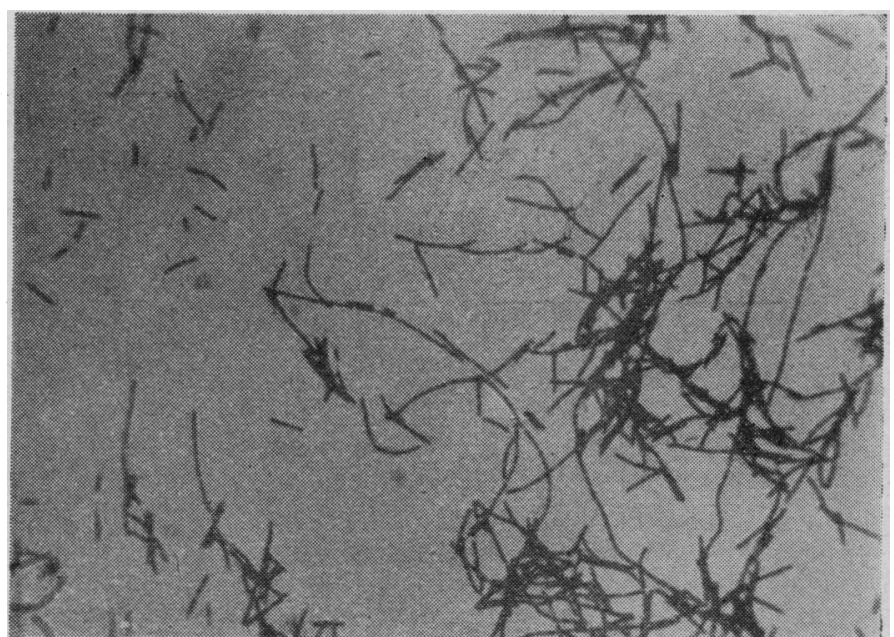

Fig. 4.-B. anthracis. Gram-positive bacilli in chains. $(\times 1,585$. $)$

In patients with a cutaneous lesion, in whom there is some doubt about the clinical diagnosis, a negative result in the direct film is significant. A furuncle can mimic a "malignant pustule." Without exception, furuncular discharge contains large numbers of polymorphonuclear leucocytes and Grampositive cocci. The exudate from a "malignant pustule," on the other hand, characteristically shows little cellular reaction, and the causative Gram-positive bacilli are commonly present in such small numbers as to escape detection by direct microscopy. Even the finding of bacilli that morphologically resemble $B$. anthracis must be interpreted with caution. The possibility of secondary infection of a "malignant pustule" by Staph. pyogenes must be considered when the direct film appears to be one of staphylococcal pus.

There is evidence to show that imported bone-meal is highly infected (18 out of 21 samples from India and Pakistan tested by the Levy Committee in 1959) (Ministry of Labour, 1959). The sterilization of meal is considered too costly to be practical. Yet despite these two facts the incidence of human infection is very low. Since full notification of all types of anthrax became compulsory in England and Wales in 1960, an average of 10 cases annually is reported from all sources. Of 70 cases 
notified between 1960 and 1966, 10 were associated with bonemeal contact, and five of these were in agricultural or horticultural workers. Thus, in view of the many hundreds of tons of potentially dangerous material imported each year, and its wide distribution to the general population, the infectivity must indeed be very low.

We are grateful to Dr. T. Parkinson and Dr. W. Stokes for allowing these cases to be published, and to Dr. R. M. Dykes and
Dr. J. J. A. Reid, medical officers of health. We are indebted to Mr. J. Harrison for preparing the photographs.

Requests for reprints should be addressed to Dr. A. H. Knight, Renal Unit, Royal Free Hospital, North-west Branch, Lawn Road, London N.W.3.

\section{REFERENCE}

Ministry of Labour (1959). Report of the Committee of Inquiry on Anthrax, Cmnd. No. 846, p. 47. H.M.S.O., London.

\title{
Timing of Atropine and Neostigmine in the Reversal of Muscle Relaxants
}

\author{
J. G. HANNINGTON-KIFF,* M.B., B.SC., F.F.A. R.C.S.
}

\begin{abstract}
Summary : The antimuscarinic effects of atropine were studied in 46 patients to whom neostigmine had been given after operation to reverse the action of a muscle relaxant. Neostigmine was given to alternate patients three minutes after, or together with, atropine, and the effects of the two procedures were compared by measuring the secretions which collected in the buccal and oropharyngeal cavities and observing the heart rate.

It was found that the glands of the oral cavity were stimulated to a greater extent when neostigmine was given with atropine than after atropine. Any dose of atropine sufficient to inhibit peristaltic movements of the bowel is more than enough to block completely secretion by the salivary glands, and the appearance of some secretion in all cases after the administration of neostigmine suggests that the bowel was at liberty to react to the neostigmine in every case, but perhaps particularly so when atropine and neostigmine were given mixed. The integrity of an anastomosis of the bowel could be endangered by vigorous peristalsis in the early postoperative period.

Electrocardiograms in about half the patients from each group confirmed earlier work that the muscarinic effects of neostigmine on the heart can be prevented by giving the atropine either before or together with the neostigmine.
\end{abstract}

\section{Introduction}

Neostigmine methylsulphate is routinely used to reverse the action of non-depolarizing muscle relaxants postoperatively, and its muscarinic effects are minimized by the administration of atropine. It is known that in certain circumstances atropine can give rise to an initial bradycardia (Innes and Nickerson, 1965) and, to avoid the possibility of a summation of the slowing effects of atropine and neostigmine on the heart, it is usual to administer atropine and wait some minutes for a tachycardia to be established before giving neostigmine. However, the need for preceding neostigmine by atropine has been questioned, since it has been shown that the initial effect of atropine and neostigmine mixture is tachycardia (Kemp and Morton, 1962 ; Baraka, 1968).

* Lecturer in Anaesthetics, University of Bristol.
It must be appreciated that it remains to be shown whether the muscarinic effects of neostigmine are as effectively blocked in organs other than the heart when given mixed with atropine rather than after atropine in the classical manner. The results are reported here of an initial study to compare the amount of secretion from the glands of the oral cavity when neostigmine is given together with and after atropine.

\section{Patients and Methods}

In a consecutive series of cases for laparotomy anaesthetized by me, tubocurarine was reversed in alternate patients with neostigmine preceded by or simultaneously with atropine. The patients may thus be divided into two groups according to the timing of the atropine and neostigmine. There was no significant difference with regard to age and sex between the two groups (see Table) and the types of abdominal operations included in each group were comparable. Forty-eight patients were investigated, but the results in two of these have been omitted, as the course of their anaesthesia was uneven.

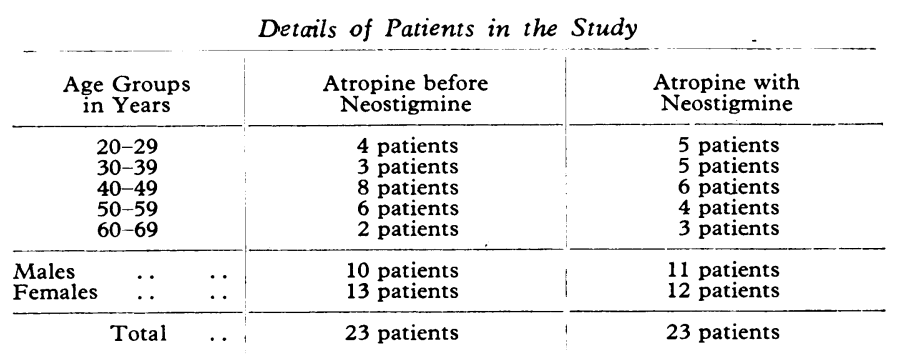

\section{Details of Anaesthesia}

Premedication was with pethidine $1 \mathrm{mg} . / \mathrm{kg}$. and atropine $0.01 \mathrm{mg} . / \mathrm{kg}$. one hour before operation. General anaesthesia was induced with intravenous thiopentone $3-4 \mathrm{mg} . / \mathrm{kg}$. and a cuffed endotracheal tube was passed after intravenous suxamethonium $0.8 \mathrm{mg} . / \mathrm{kg}$. Anaesthesia was maintained with nitrous oxide and oxygen with mechanical ventilation, and muscle relaxation was continued with intravenous tubocurarine $5-7 \mathrm{mg}$. $/ \mathrm{kg}$., which was reversed with neostigmine $0.04 \mathrm{mg}$./ $\mathrm{kg}$. and atropine $0.02 \mathrm{mg}$. $/ \mathrm{kg}$. The atropine was given either three minutes before or together with the neostigmine in alternate cases. 